\title{
Quem é Maria de Nazaré? O testemunho bíblico na vida da Igreja ${ }^{1}$
}

\author{
Who is Mary of Nazareth? \\ The biblical witness in the life of the Church
}

Luisa Maria Almendra

\section{Resumo}

Este artigo pretende focalizar o leitor numa compreensão de Maria, a partir do testemunho bíblico, entendendo-o como um eco do lugar que Maria ocupou e viveu como mãe de Jesus e como discípula entre os discípulos. Pretende uma apresentação bíblico-teológica, capaz de estabelecer paralelos e diferenças entre as narrativas de Evangelho. O ponto de partida é o testemunho bíblico sobre Maria, na constatação dos seus silêncios, mas também da sua sobriedade e diversidade. Entre os aspetos mais significativos sublinha-se a admirável simbiose entre as dimensões de mãe e discípula. É ela quem nos prepara para uma releitura teológica do sim de Maria como a realização de um sinal oferecido à história: o dom de salvação. Compreende-se, então, que Maria tenha permanecido como a 'bendita entre as mulheres', a primeira entre os discípulos e discípulas, interpelando constantemente o modo como entendemos e vivemos a nossa relação com Deus, e a nossa devoção a Maria.

Palavras-chave: Silêncio. Sobriedade. Diversidade. Mãe. Discípula. Sinal. Bendita.

\section{Abstract}

This article intends to focus the reader in understanding Mary,

\footnotetext{
${ }^{1}$ Este artigo resulta de uma apresentação no VII Simpósio de Teologia PUC-Rio, sobre: Maria: Escritura, Teologia e Religiosidade, no decorrer do Ano Jubilar Mariano: 300 anos de história.
} 
assuming the biblical narrative as an echo of the place Mary occupied and lived as the mother of Jesus and as a disciple among the disciples. It seeks a biblical-theological presentation, capable of establishing parallels and differences between the Gospel narratives. The starting point is the biblical testimony about Mary, observing the narrative silences, but also its sobriety and diversity. Among the most significant aspects, we place the admirable symbiosis between the dimensions of mother and disciple. It is this symbiosis that prepares us for a theological reading of Mary's 'yes', as the realization of a sign offered to history: Jesus the gift of salvation. It is understood, then, that Mary has remained as the 'blessed among women', the first among the disciples, questioning constantly how we understand and live our relationship with God, and our devotion to Mary.

Keywords: Silence. Sobriety. Diversity. Mother. Disciple. Sign. Blessed.

\section{Introdução}

Nunca teremos certezas sobre o papel de Maria na elaboração dos primeiros testemunhos orais e escritos que constituem a base narrativa dos textos NT sobre a sua própria vida e a vida de Jesus. No entanto, este facto não impediu que Maria fosse a pessoa, historicamente, antes de o ser teologicamente, para a qual a Igreja convergiu, assumindo-a como mãe de todos os cristãos. O texto de At 1,14 constitui um eco importante do modo discreto e incontronável como a comunidade cristã entendia a presença e a pessoa de Maria.

At $1,{ }^{14}$ E todos unidos pelo mesmo sentimento, entregavam-se assiduamente à oração, com algumas mulheres, entre as quais Maria, mãe de Jesus, e com os irmãos de Jesus. (cf. 2,44; 6,1; 21,20; 24,5; Gl 1,18; 2,10).

Esta presença ficou igualmente bem explícita na ênfase singular que os diferentes autores bíblicos do NT atribuíram a Maria, cada um assinalando a sua especificidade própria: Lc 1-2; At 1-2 (textos que marcam o início de cada um dos livros: Evangelhos e Atos); Mt 1,21-23; (texto situado no início do Evangelho); Mc 3,20-21; 6,1-6; (dois textos situados durante o ministério de Jesus); Jo 2,4; 19,27 (dois textos que marcam início e fim da narrativa deste Evangelho). 
Como parte integrante de uma tipologia bíblica progressiva e explicativa, os autores bíblicos tornaram Maria naquela que participa da plena realização da presença de Deus na história: Maria é a mulher vestida de sol, grávida que dá à luz um filho varão, que governará todas as nações com cetro de ferro: Jesus Cristo (Ap 12,1-6). Não permitindo que, como figura da Igreja, Maria de Nazaré centralizasse totalmente em si a Igreja. Na expressão 'Fazei o que ele vos disser' (Jo 2,4), Maria torna-se um lugar de mediação e de caminho para Jesus.

Existe algo de semelhante na relação que tendemos a estabelecer entre Maria e a história do povo da aliança. A fé cristã viu sempre uma espécie de prefiguração de Maria nas matriarcas de Israel (Sara, Rebeca, Raquel e Lia - todas marcadas por especial intervenção de Deus, Gn 17 // Mt 1,2021; Rm 9,9-10; Hb 11,11; 1Pe 3,6); antecipou-a nas suas heroínas (Miriam, a irmã de Moisés, Dt 24,9; Débora - a profetiza Jz 4,4-5, Judite e Ester - as mulheres fortes do seu povo, Jud 8-9; Est 5); e naquelas que viveram o dom de uma maternidade extraordinária (Ana, mãe de Samuel,1Sm 1-2 // Lc 2,36) e a 'almah / parthénos, a mãe do Immanuel, Is 7,14 // Mt 1,23).

Será no âmbito do eco da comunidade cristã que situaremos a pergunta: Quem é Maria de Nazaré? Tentando encontrar uma possível resposta no testemunho bíblico e no seu impacto na vida da Igreja, não temos dúvidas de que tudo o que possamos dizer sobre Maria transporta o eco do testemunho bíblico que foi construído e que construiu a Igreja. ${ }^{2}$ Dificilmente admitiríamos Maria sem a Igreja ou a Igreja sem Maria. ${ }^{3}$ No entanto, esta compreensão, aparentemente compreensível e convincente, obriga-nos a cuidados linguísticos e pastorais sérios e relevantes. Por isso, com a comunidade cristã dos primeiros tempos, temos de aprender e vigiar, constantemente, o modo como compreendemos, relacionamos e situamos Maria na nossa vida pessoal de fé e nas nossas comunidades cristãs. O testemunho dos autores do NT e das comunidades cristãs ensinam-nos que o papel determinante de Maria na Igreja não pode confundir-se com o de Jesus Cristo ou até mesmo o do Espírito Santo. Maria tem um lugar próprio na história da salvação, que tem o seu centro na pessoa de Jesus Cristo. Torna-se, por isso, de extrema relevância conhecer sempre melhor o testemunho bíblico das primeiras comunidades cristãs, para que possamos entender e conhecer cada vez melhor quem é Maria de Nazaré e o seu impacto no seu tempo e nos tempos da Igreja.

${ }^{2}$ Cf. Cf. GASPERIS, F. R. Maria di Nazaret: Ícona di Israele e della Chiesa. Magnano: Edizioni Qiqajon, 1997, pp. 111-125.

${ }^{3}$ Cf. PELLETIER, A. M. “Marie, verus Israel et mère de l'Église”. Christus 183 (1999), p. 289. 


\section{Maria no testemunho bíblico do NT}

O cuidado que a comunidade cristã manifesta, no testemunho bíblico que nos oferece sobre Maria, parece querer preservar o que nunca poderá ser dito ou traduzido por palavras humanas sobre a pessoa de Maria. Por isso, devemos ter consciência de que, embora possamos saber algumas coisas, haverá sempre muito por descobrir e entender sobre Maria. Em cada tempo, a Igreja e cada um de nós tem direito a perguntar-se: "Quem é Maria de Nazaré?", sabendo que entre um grande número de cristãos, bastaria que tentássemos pedir que nos fundamentassem na Escritura aquilo que afirmam sobre Maria, para nos darmos conta de que prevalecem ideias muito confusas. Muitas destas ideias são fruto de sentimentos que contrastam com a sobriedade do testemunho bíblico. Na sua grande maioria, estes cristãos não têm qualquer noção de quanto poderiam aproveitar se aprofundassem e construíssem a sua imagem de Maria num conhecimento maior dos textos do NT. Em muitos cristãos não existe uma consciência nítida de que, à margem da Escritura, existem demasiadas probabilidades de construírem uma imagem, uma relação e uma devoção, que pode basear-se sobretudo na engenhosa imaginação e no simples sentimento. ${ }^{4}$

Por isso, a nossa convicção é a de que o conhecimento dos textos bíblicos que nos falam de Maria não é algo facultativo. Não é sério nem saudável dizermos: já fui ao Santuário de Fátima ou de N.S. Aparecida, mas nunca li o que se diz e a forma como se fala de Maria no NT. Principalmente, se desejamos viver uma devoção íntegra a Maria (não uma mariolatria). Não podemos ignorar, neste âmbito, que Maria não está de todo ausente nas tensões entre as a Igrejas (Católicos e Protestantes...). Ainda que ela não seja o motivo de separação, é nela que se polarizam e refratam alguns fatores de desunião.

\subsection{Os silêncios da Escritura}

É um facto que só a Escritura bem lida e bem interpretada pode, em definitivo, oferecer-nos o que existe mais autêntico em Maria. Porém, quando nos perguntamos o que é que a escritura nos diz, então, acerca de Maria, a resposta imediata surpreende: diz-nos muito pouco. Os textos de Evangelho e os demais escritos neotestamentários comportam-se com uma singular discrição em relação a Maria. As referências, diretas e indiretas a Maria, são

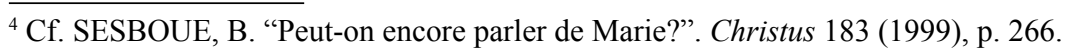


muito escassas. Se considerarmos a afirmação feita em At 1,14 uma afirmação do lugar que Maria assumiu na comunidade cristã dos primeiros tempos, como um indicador fundamental para a compreensão da comunidade cristã na sua relação com Jesus de Nazaré, o Cristo e Senhor, como explicar a sobriedade e silêncio dos autores bíblicos?

Uma primeira constatação emerge no inicio do texto de Evangelho de Mateus e de Lucas. Ambos os textos sugerem que, associada ao nascimento de Jesus, Maria é sinal de início de um tempo novo. No texto de Mateus a menção a Maria é muito discreta: emerge no final surpreendente da sua genalogia $(1,16)$, no anúncio a José (Mt 1,18-25), e mais tarde no episódio sobre a verdadeira família de Jesus (Mt 12,46-51). Estamos num texto onde a centralidade na pessoa de José parece desfocar qualquer informação que estas narrativas possam oferecer sore Maria. Não é este o caso das narrativas do texto de Lucas, a que podemos recorrer sempre que desejamos falar sobre Maria. No entanto, também, este texto não está preocupado em oferecer-nos uma biografia de Maria. O foco dos dois primeiros capítulos não é Maria, mas a a salvação que Deus, em Jesus, oferece à história:

...para dar a conhecer ao seu povo a salvação $(\operatorname{Lc} 1,77)$... pela remissão dos seus pecados...porque meus olhos viram a Salvação (Lc 2,30); ... e o meu espírito se alegra em Deus, meu Salvador $(\operatorname{Lc} 1,47)$...e nos deu um Salvador poderoso, na casa de David, seu servo (Lc 1,69) ...hoje, na cidade de David, nasceu-vos um Salvador, que é o Messias Senhor (Lc 2,11).

Curiosamente, o testemunho do texto de Evangelho de João demarca-se não pelas referências a Maria, mas pelo modo como o faz, tratando-a sempre, desde o início até ao fim do ministério de Jesus, como a "mãe de Jesus":

Ao terceiro dia, celebrava-se uma boda em Caná da Galileia e a mãe de Jesus estava lá... Como viesse a faltar o vinho, a mãe de Jesus disse-lhe: "Não têm vinho!" ...sua mãe disse aos serventes: "Fazei o que Ele vos disser!" ...Depois disto, desceu a Cafarnaum com sua mãe, os irmãos e os seus discípulos, e ficaram ali apenas alguns dias (Jo 2,1-12); Junto à cruz de Jesus estavam, de pé, sua mãe e a irmã da sua mãe, Maria, a mulher de Clopas, e Maria Madalena... Então, Jesus, ao ver ali ao pé a sua mãe e o discípulo que Ele amava, disse à mãe: "Mulher, eis o teu filho!" Depois, disse ao discípulo: "Eis a tua mãe!". E, desde aquela hora, o discípulo acolheu-a em sua casa (Jo19,25-27). 
Fora dos textos de Evangelho, o NT só muito raramente se refere a Maria. Situa-se aqui a referência a Maria na comunidade cristã, depois da Ascensão: E todos, unidos pelo mesmo sentimento, entregavam-se assiduamente à oração, com algumas mulheres, entre as quais Maria, mãe de Jesus, e com os irmãos de Jesus (At 1,14); considerada por muitos exegetas como uma menção muito discreta. ${ }^{5}$ Uma vez que se refere a sua presença entre os discípulos, mas sem qualquer intenção de referir o seu papel na vida da comunidade pós -pascal. Esta posição é reforçada pela ausência a qualquer menção a Maria no kerigma primitivo (At 1,22; 2,17-36; 10,36-43). O próprio Paulo, focalizado na morte e ressurreição de Cristo, não concede, literária nem teologicamente, uma importância significativa a Maria: nunca a menciona diretamente, limitando-se a afirmar que: "Quando se cumpriram os tempos, Deus enviou o seu filho, nascido de uma mulher" (Rm 1,3). Não sendo possível falar de Maria de um modo mais neutro.

\subsection{Sobriedade e diversidade}

A sobriedade e a diversidade das referências bíblicas a Maria dificultam a nossa tarefa de reconstruir a figura e o papel de Maria na vida de Jesus e da Igreja. Não existe uma imagem uniforme, não dizem todos o mesmo. Podemos eventualmente perguntar quem tem razão. Um exemplo é o modo como o texto de Marcos formula a pergunta de Jesus: "Quem é minha mãe e quem são os meus irmãos?" (Mc 3,33). A sua resposta quase parece subentender que Maria não pertenceria à comunidade escatológica de Jesus: E, percorrendo com o olhar os que estavam sentados à volta dele, disse: "Aí estão minha mãe e meus irmãos. Aquele que fizer a vontade de Deus, esse é que é meu irmão, minha irmã e minha mãe" (Mc 3,34-35). Alguns autores chegam mesmo a interrogar-se se o autor do texto de Marcos não teria alargado a Maria a permanente incompreensão dos discípulos durante o ministério de Jesus. Seja como for, a descrição positiva de Lc 8,19-21 ( ${ }^{20}$ Anunciaram-lhe: "Tua mãe e teus irmãos estão lá fora e querem ver-te". ${ }^{21}$ Mas Ele respondeu-lhes: "Minha mãe e meus irmãos são aqueles que ouvem a Palavra de Deus e a põem em prática") vinca bem as qualidades de Maria para fazer parte desta nova família de Jesus. Ninguém como ela escutou e colocou a palavra em prática.

Impõe-se, portanto, respeitar a singularidade dos textos bíblicos. Se o NT não é demasiado explícito a propósito de Maria, isto não altera em nada a

${ }^{5}$ Cf. NADEAU, M.T. Quién es María? Hablar de la Virgen Hoy. Madrid: San Pablo, 2002, p. 15. 
particularidade do seu papel no plano divino da salvação. É um erro medir o que Maria representa para a Igreja e para todos os cristãos a partir do número de vezes a que a Escritura se refere a ela. Não há dúvida de que, querendo saber ou dizer demasiado sobre Maria, podemos traí-la e, simultaneamente, trair o Evangelho e o testemunho das primeiras comunidades. É neste sentido, que exegetas nos incentivam a não tentarmos compensar as poucas referências bíblicas que temos a Maria, apelando a um silêncio, o mesmo em que se abriga o mistério indizível do Deus-connosco que se gerou no seio de Maria. ${ }^{6} \mathrm{O}$ silêncio dessa gestação e dos 30 anos de vida, dos quais pouco ou nada se sabe, será sempre inspirador de uma compreensão inexplicável.

\subsection{Maria discípula e mãe}

O modo cuidadoso e preciso com que os autores bíblicos do NT falam de Maria permite-nos intuir que para a primeira comunidade dos discípulos de Jesus, o Messias e Senhor, Maria de Nazaré, a mãe de Jesus, não foi, em primeiro lugar, alguém importante que eles deviam admirar ou venerar. Maria foi sobretudo, alguém que estava ali, na comunidade cristã, ao lado de todos os discípulos, que procuravam compreender e seguir Jesus. Entrevemo-lo nas palavras de Jesus, conservadas na memória das primeiras comunidades cristãs; palavras que instituem um novo horizonte de relações e presença.

Mt 12, ${ }^{46}$ "Estava Ele ainda a falar à multidão, quando apareceram sua mãe e seus irmãos, que, do lado de fora, procuravam falar-lhe. ${ }^{47}$ Disse-lhe alguém: "A tua mãe e os teus irmãos estão lá fora e querem falar-te". ${ }^{48} \mathrm{Jesus}$ respondeu ao que lhe falara: "Quem é a minha mãe e quem são os meus irmãos?" ${ }^{49} \mathrm{E}$, indicando com a mão os discípulos, acrescentou: "Aí estão minha mãe e meus irmãos; ${ }^{50}$ pois, todo aquele que fizer a vontade de meu Pai que está no Céu, esse é que é meu irmão, minha irmã e minha mãe". (Mc 3,31-35; Lc 8,19-21).

No entanto, não obstante ela aparecer como uma discípula entre os muitos discípulos, é possível suspeitar que ela não tenha sido uma figura singular e marcante para a comunidade cristã. Na verdade, Maria era a mãe de Jesus, o Jesus que eles amavam. Mas ela era particularmente "aquela que tinha

\footnotetext{
${ }^{6}$ Cf. BROWN, R. E.; DONFRIED, K. P.; FITZMYER, J. A.; REUMANN, J. (Eds.). Mary in the New Testament. Philadelphia / New York: Fortress / Paulist, 1978.
} 
acreditado"; a primeira a acolher e guardar, viver e compreender a Palavra de Deus, em Jesus, o filho do seu seio (Lc 1,31; 11,27-28). Não surpreende, por isso, que as palavras de Isabel: "Bendita és tu porque acreditaste..." (Lc 1,45) tenham sido sempre e continuem ainda hoje a ser a expressão mais bela e mais autêntica sobre Maria na vida da Igreja. ${ }^{7}$ Maria é a mãe de Jesus, mas é também a primeira discípula, que acreditou em tudo em tudo que lhe foi dito da parte de Deus. ${ }^{8}$ É neste seu inexplicável acreditar que ela, sendo verdadeiramente mãe de Jesus, possa considerar-se a primeira discípula.

É neste sentido que a tentativa de compreender a reserva e a singeleza da narrativa bíblica sobre Maria de Nazaré. Alguns autores afirmem que a grandeza de Maria, na vida das primeiras comunidades cristãs, tenha sido a sua capacidade de ser testemunho de fé, capaz de gerar e fundamentar a memória meditativa da primeira comunidade: ${ }^{9}$

Lc 2, ${ }^{9}$ Quanto a Maria, conservava todas estas coisas, ponderando-as no seu coração. ${ }^{20} \mathrm{E}$ os pastores voltaram, glorificando e louvando a Deus por tudo o que tinham visto e ouvido, conforme lhes fora anunciado... Sua mãe guardava todas estas coisas no seu coração. ${ }^{52} \mathrm{E}$ Jesus crescia em sabedoria, em estatura e em graça, diante de Deus e dos homens.

No entanto, Maria não se demarcava simplesmente por ser a mãe de Jesus, ela estava no seio da comunidade cristã como a mãe e a garantia de uma tradição oral segura e de sabedoria meditada. ${ }^{10}$ Neste sentido, podemos igualmente suspeitar que Maria tenha sido o testemunho mais seguro de referência e de consulta para a formação da tradição oral e escrita que está na base dos textos do Novo Testamento. A verdadeira "mestra" da comunidade de Jerusalém. Entrevemo-lo de um modo velado, mas surpreendente, no texto do "Magnificat". Ali é onde Maria nos é descrita como a primeira que foi capaz de cristianizar, oralmente e de maneira profética, toda a tradição de Israel (Lc 1,46-55).

\footnotetext{
7 JOÃO PAULO II. Redemptoris Mater, 1987, nº. 12-21.25-27.36.42.

${ }^{8}$ Cf. SESBOUE, B. "Marie, celle qui a cru”. Christus 183 (1999), p. 269. B. Sesboue refere-se à obra de MIRAVALLE, M. I. (Ed.). Mary, Coredemptrix, Mediatrix, Advocate. Theological Foundations. Towards a papal definition? Santa Barbara, CA: Queenship Publishing, 1995.

${ }^{9}$ Cf. GASPERIS, F. R. Maria di Nazaret: Ícona di Israele e della Chiesa, pp. 12-18.

${ }^{10} \mathrm{Cf}$. PERRIER, P. Karozoutha. Annonce orale de la bonne nouvelle em araméen et évangiles gréco-latin, Paris: Médiaspaul - Montréal / Paulines, 1986, pp. 511-534.
} 


\section{Maria na vida da Igreja}

É um fato, que todas as referências bíblicas a Maria estão orientadas para a pessoa de Jesus e a salvação que ele realiza na história humana. Maria não se entende sem a pessoa de Jesus Cristo. Nem mesmo os chamados "Evangelhos da Infância", onde a atenção parece recair sobre Maria, se pode dizer que ela esteja em primeiro plano. Os autores bíblicos nunca a referem por ela mesma. O seu testemunho, construído sob uma forte intertextualidade bíblica, foi antes de mais uma tentativa de resposta às muitas perguntas das primeiras comunidades cristãs. No decorrer da vida da Igreja e, ainda hoje, é sob este testemunho que podemos repensar as origens humana e divina de Jesus. Sem dúvida que Maria não se confunde com Jesus, nem Jesus com Maria. A sua individualidade na resposta ao desígnio de Deus para a sua vida não a confunde nem a separa, pelo contrário situa-a na singularidade de uma relação com a pessoa de Jesus Cristo.

Por isso, não nos surpreende que, como os textos de Evangelho, todos os testemunhos posteriores dos Padres da Igreja sublinham a relação entre Jesus e Maria. Citamos, a título de exemplo, Inácio de Antioquia (110), o primeiro autor a mencionar Maria, fora dos textos bíblicos do NT. Sempre que se refere a Maria, Inácio de Antioquia fá-lo num contexto teológico, preocupado em afirmar vigorosamente a realidade da incarnação: "Jesus nasceu de Maria e de Deus". ${ }^{11}$

\subsection{No sim de Maria: o sinal acontece e salva}

A citação explícita do texto de Mateus - Tudo isto aconteceu para se cumprir o que o Senhor tinha dito pelo profeta: Eis que a virgem conceberá e dará à luz um filho; e hão de chamá-lo Emanuel, que quer dizer: Deus connosco (Mt 1,22.23) - só se entende à luz do contexto narrativo original de Is 7,4-14. Vivia-se, então, um momento de grande angústia, pânico e guerra eminente na história de Israel. Deus não está indiferente e por meio do seu profeta envia uma mensagem ao rei Acaz:

"Tranquiliza-te, tem calma, não temas... Se não o acreditares, não subsistirás... O Senhor mandou dizer de novo a Acaz: "Pede ao Senhor

\footnotetext{
${ }^{11}$ Cf. IGNACIO DE ANTIOQUIA. “Carta a los esmirniotas III”. Disponível em: < http://www. apologeticacatolica.org/pt/patristica/patrist12.html>. Acesso em 22 de março de 2017.
} 
teu Deus um sinal, quer no fundo dos abismos, quer lá no alto dos céus". Acaz respondeu: "Não pedirei tal coisa, não tentarei o Senhor". Isaías respondeu: "Escuta, pois, casa de David: Não vos basta já ser molestos para os homens, senão que também ousais sê-lo para o meu Deus? Por isso, o Senhor, por sua conta e risco, vos dará um sinal. Olhai: a jovem está grávida e vai dar à luz um filho, a quem dará o nome de Emanuel" (Is 7,4-14).

O momento histórico do profeta Isaías não é de modo algum o ideal para uma jovem mulher engravidar. No entanto, Deus não desiste da história, mesmo nos seus momentos mais complexos e difíceis. Através do profeta, Deus procura incutir a esperança no Rei Acaz. O rei hesita, mas Deus não, e decide por sua conta e risco anunciar um sinal. O facto de se dizer "a jovem" (uso do artigo) sugere que esta jovem é única, é aquela e não outra e a gravidez desta jovem é um sinal sério dado por Deus a um povo que vivia uma sequência de vicissitudes históricas e políticas difíceis. O profeta Isaías deseja que o povo acredite que Deus está presente à sua circunstância histórica difícil e caminha pacientemente com eles. O seu Deus não é o grande ausente; é um Deus que se compromete não só com a reconstrução da vida do povo, mas ele próprio se afirma como um Deus com; um Deus que promete habitar no meio deste povo: ser Deus-connosco ('immanû'el). Segundo o profeta Isaías, Deus oferece um sinal no acontecimento de uma vida nova, como o são todos os nascimentos; virá, portanto, no contexto de um sinal surpreendente, que só poderá ser reconhecido com o olhar da fé.

No sim de Maria, o inexplicável de um Deus que envia o seu anjo a uma pequena cidade da Galileia, o sinal acontece. Muitos exegetas entreviram este sinal na mudança do termo hebraico 'almah - a mulher jovem, atraente pela sua beleza, casada ou não, mas geralmente sem filhos - no termo grego parthénos e latino virgo (LXX e Vg). Esta mudança sugere uma consonância com a dimensão inexplicável do sinal dado por Deus: que uma jovem engravide é algo natural, mas uma virgem não. Porém, não se trata apenas de um jogo de palavras ou de uma tradução bem calculada. Trata-se de tornar Maria naquela sob a qual se oferece o sinal do inexplicável de Deus na história, que é Jesus Cristo. Esse sinal que a comunidade joanina soube formular de um modo excelente quando, nas Boas de Caná, alude à transformação da água em vinho como: “... o primeiro dos sinais, Jesus o fez em Caná da Galileia” (Jo 2,11).

Que sinal é este? O mesmo da anunciação: na pessoa de Jesus Cristo, Deus está plenamente na história. Por isso, não obstante as palavras de Je- 
sus em Caná, Maria é a primeira a entrevê-lo. O autor bíblico não hesita em desenhar a total confiança de Maria no seu filho; um filho que durante trinta anos não lhe dera qualquer sinal de diferença dos demais jovens do seu tempo. Aparentemente, Maria não tem um motivo que sustenha tamanha confiança. Vivera simplesmente até ao momento das tais palavras que lhe foram "ditas da parte do Senhor"; elas foram sempre o seu único amparo. Esta intervenção de Maria, em Caná da Galileia, realiza o seu sim da anunciação, distinguindo o papel que Maria terá sempre na comunidade cristã: a mulher do sim e da fé; a mãe da relação íntima e única, que saberá estar sempre atenta e interceder.

\subsection{Maria: a 'bendita' entre as mulheres}

A expressão de Isabel "Bendita és tu entre as mulheres" (Lc 1,42), raramente jamais no judaísmo a um ser humano, ${ }^{12}$ é sublime, porém deve ser entendida corretamente. Deve-se evitar a interpretação de que só ela, Maria apenas, "entre as mulheres", sabia como agradar a Deus. O texto do Evangelho, seja na versão grega seja na versão latina, sublinha que se trata de um "in", "entre as mulheres", colocando Maria na frente de uma grande procissão de mulheres, de sucessivas gerações desde que o mundo começou.

A nossa memória histórica luta para reviver a vida de Maria, como uma mulher de Israel, entre as mulheres do seu tempo. O nosso entendimento tenta recuperar a sua vida escondida em Nazaré, onde nada parecia digno de atenção, porém onde, verdadeiramente, se toca o mistério da profunda humanidade e divindade de Jesus, descrito em Gl 4,4 simplesmente como "nascido de mulher".

$\mathrm{Na}$ verdade, Maria distingue-se por ser uma mulher de escuta e de entrega ao projeto oculto de Deus. Foi nesta escuta e entrega que Jesus foi gerado. Foi nesse ato de fé indizível e irrepetível que Maria gerou e susteve a Igreja. Desde a anunciação até ao Gólgota. Tal como Jesus, também ela não foi poupada ao desespero, expresso nas palavras do salmo: "Meu Deus, por que me abandonaste". Porém, Maria permaneceu presente até o fim. O autor bíblico faz questão de a colocar lá, vivendo com o seu filho a prova da contradição, "ponderando no seu coração" ("unindo", de acordo com o significado da palavra grega Lc 2,19), tentando entender como também naquela perda se unia à evidência de um fracasso absoluto com a confiança total e sem palavras na certeza de que Deus salva.

${ }^{12}$ Baruc attah adonay (expressão usada apenas para Deus, que marca o início do Shabbath) Cf. Jud 13,18 e 14,7 . 
Esta é a fé do "coração sábio" de Maria, evocada em Pr 14,33 (A sabedoria repousa no coração ponderado); o coração que Salomão pediu a Deus em sua oração (1 Reis 3,9). E é a partir deste coração que Maria adere ao plano oculto de Deus e que Jesus é gerado. É esta a fé com que Maria gera e está presente na Igreja, testemunhando e suscitando uma fé corajosa, sem imagens idolátricas de Deus, que a cruz contradiz e denuncia. É nesta mulher, associada à ação divina que, como cantava Santo Anselmo, a Igreja inteira é convidada a reconhecer-se maternalmente gerada, a fim de trazer ao presente, tantas vezes obscuro, em que vivemos, o testemunho da vitória ressuscitado, apesar de todas as evidências em contrário

\subsection{A nossa relação e devoção a Maria}

Antes de concluir esta reflexão, centrada no testemunho bíblico das primeiras comunidades cristãs, parece-me importante fazer, ainda, um breve paralelo com o lugar que Maria ocupa hoje no culto e na oração cristã. ${ }^{13}$ Desde o séc. V-VI a devoção a Maria se desenvolveu no Oriente sob a forma de festa litúrgica (Maria Theotokos; Natividade de Maria; Apresentação no templo; a Anunciação; a Dormição). No ocidente, estas festas começam um século depois (séc. VII). Porém, seria um erro pensarmos que a devoção a Maria se reduz a festas litúrgicas ou que esta devoção seja um fim em si mesmo. São muito oportunas as palavras de Paulo VI:

Encontrareis Maria, em definitivo, se tiverdes o escrupuloso cuidado de a situar no conjunto do mistério cristão, porque o culto a Maria não é um fim em si mesmo, mas a via mestra que nos conduz a Cristo e, nele, à glória de Deus e ao amor à Igreja (Paulo VI, no Congresso Internacional das Congregações Marianas, 1963). ${ }^{14}$

Neste contexto, como situar a questão delicada de rezarmos a Maria? Podemos invocá-la verdadeiramente, implorar o seu auxílio e apelar à sua intercessão? O que é constitutivo de uma autêntica oração a Maria? Uma das

${ }^{13}$ Consideram que não é muito correto falar de 'culto mariano', mas sim de 'culto cristão' a Maria [cf. PAULO VI. Marialis Cultus. $\mathrm{N}^{\circ}$ 66. Disponível em: <http://w2.vatican.va/content/ paul-vi/pt/apost_exhortations/documents/hf_p-vi_exh_19740202_marialis-cultus.html>. Acesso em 12 de janeiro de 2017; NADEAU, M.T. Quién es María? Hablar de la Virgen Hoy. Madrid: San Pablo, 2002, p. 117].

${ }^{14}$ Cf. NADEAU, M.T. Quién es María? Hablar de la Virgen Hoy. Madrid: San Pablo, 2002, p. 126. 
orações de intercessão a Maria, mais antigas, data do séc. III, da nossa era (Sub tuum praesidium - Sob a tua proteção). Esta oração começa com as palavras: "Sob o teu amparo nos colocamos, Santa mãe de Deus....". ${ }^{15}$ Uma outra oração é 'Salve Regina' (XII). E, neste contexto, o que dizer da 'Ave Maria', a mais difundida de todas as orações a Maria? Talvez nem todos saibam que a oração da Ave Maria não apareceu de uma vez só, como nós a conhecemos hoje. Na sua forma original, esta oração continha apenas a primeira parte, que une a saudação de Isabel a Maria em Lc 1,41-42 à do anjo em 1,28: Ave Maria, cheia de graça, o Senhor é contigo, bendita és tu entre as mulheres e bendito o fruto do teu ventre Jesus. Foi assim que se rezou até ao séc. IX. Foi só no séc. X que se juntou a invocação: "Santa Maria, mãe de Deus, rogai por nós pecadores...". Porém, a sua forma definitiva só aparece mais tarde, no breviário de Pio V (1563). ${ }^{16}$

Não temos dúvidas de que todos temos de nos questionar sobre o sentido da oração de intercessão que dirigimos a Maria. Nem sempre a entendemos como "uma oração a Deus, que é o único que a pode escutar e responder por ela". ${ }^{17}$ Só existe um culto, e este é unicamente a Deus, aquele em que vamos ao Pai através do Filho, no Espírito Santo. Por isso, por muito que concedamos a Maria, legitimamente, toda a importância e honra que merece a sua total adesão à vontade de Deus e cooperação na história da salvação, nada altera o fato de que o verdadeiro refúgio dos cristãos se encontra só na Trindade. Toda a devoção a Maria que marginaliza Jesus Cristo é errada. Nunca podemos perder de vista o papel único de mediadora, bem vivido e testemunhado pelas comunidades cristãs, na narrativa bíblica (cf. Jo 2,1-12). ${ }^{18}$ Uma autêntica oração a Maria integra sempre um compromisso real à fidelidade de Deus, manifestada em Jesus Cristo.

\footnotetext{
${ }^{15}$ Cf. MERCENIER, F. "La plus ancienne prière à la sainte Vierge". Questions Liturgiques 25 (1940), pp. 33-36.

${ }^{16}$ Cf. JOUNEL, P. "Le culte de Marie". In: MARTIMORT, A. G. L'Église en Prière IV: La liturgie et le temps. Paris: Desclée, 1983, pp. 158-159.

${ }^{17}$ Cf. GROUPE DES DOMBES. Marie dans le dessein de Dieu et la communion des saints. Tome I: Dans l'histoire et l'Écriture. Paris: Bayard / Centurion, 1997, pp. 33 e 53.

${ }^{18}$ Cf. a este propósito: VATICANO II. Lumen Gentium. № ${ }^{\circ}$ 67. Disponível em: $<$ http://www. vatican.va/archive/hist_councils/ii_vatican_council/documents/vat-ii_const_19641121_ lumen-gentium_po.html $>$. Acesso em 19 de janeiro de 2017; VATICANO II. Gaudium et Spes. $\mathrm{N}^{\circ}$ 19. Disponível em: < http://www.vatican.va/archive/hist_councils/ii_vatican_council/documents/vat-ii_const_19651207_gaudium-et-spes_po.html>. Acesso em 06 de fevereiro de 2017.
} 
Por isso, não nos devem surpreender as palavras do Papa Francisco, ditas recentemente, na sua peregrinação a Fátima (Maio 2017):

"Peregrinos com Maria... Qual Maria? Uma 'Mestra de vida espiritual', a primeira que seguiu Cristo pelo caminho 'estreito' da cruz dando-nos o exemplo, ou então uma Senhora inatingível e, consequentemente, inimitável? A 'Bendita por ter acreditado', sempre e em todas as circunstâncias nas palavras divinas, ou então uma santinha a quem se recorre para obter favores a baixo preço? A Virgem Maria do Evangelho venerada pela Igreja orante, ou uma esboçada por sensibilidades subjetivas que a veem segurando o braço justiceiro de Deus pronto a castigar: uma Maria melhor do que Cristo, visto como Juiz impiedoso; mais misericordiosa que o Cordeiro imolado por nós?"

"Os pastorinhos viram a 'Mãe do Céu' e muitos outros, na sua esteira, também a quiseram ver. Contudo, a Virgem Mãe não veio aqui para que a víssemos; para isso, teremos a eternidade inteira, naturalmente, se formos para o Céu. Mas Ela, antevendo e advertindo-nos para o risco do Inferno aonde leva a vida sem Deus e profanando Deus nas suas criaturas, veio lembrar-nos a Luz de Deus que nos habita e cobre".

"Sempre que olhamos para Maria, voltamos a acreditar na força revolucionária da ternura e do carinho. Esta dinâmica de justiça e de ternura, de contemplação e de caminho ao encontro dos outros é aquilo que faz d'Ela um modelo eclesial. Possamos, com Maria, ser sinal e sacramento da misericórdia de Deus que perdoa sempre, perdoa tudo".

"Desde o início, quando permaneci longamente em silêncio na Capelinha das Aparições, acompanhado do silêncio orante de todos os peregrinos, criou-se um clima de recolhimento e contemplação, no qual se concentraram vários momentos de oração. E no centro de tudo estava e está o Senhor Ressuscitado, presente no meio do seu Povo na Palavra e na Eucaristia".

"Temos diante dos olhos São Francisco Marto e Santa Jacinta, a quem a Virgem Maria introduziu no mar imenso da Luz de Deus e aí os levou a adorá-Lo. Daqui lhes vinha a força para superar contrariedades e sofrimentos. A presença divina tornou-se constante nas suas vidas, como se manifesta claramente na súplica instante pelos pecadores e no desejo permanente de estar junto a 'Jesus Escondido' no sacrário".

"Queridos irmãos, rezamos a Deus por Maria, com a esperança de que nos escutem os homens; e dirigimo-nos aos homens com a certeza de que Deus nos vale", 
Continuou o Papa, empregando, então, as palavras de Lúcia:

"Ele criou-nos como uma esperança para os outros, uma esperança real e realizável segundo o estado de vida de cada um. Ao 'pedir' e 'exigir' o cumprimento dos nossos deveres de estado [carta da irmã Lúcia, 28/ II/1943], o Céu, através de Maria, desencadeia aqui uma verdadeira mobilização geral contra esta indiferença que nos gela o coração e agrava a miopia do olhar". ${ }^{19}$

Lembrando também uma expressão muito usada pelo Papa João Paulo II, o Papa Francisco concluiu: "Sob a proteção de Maria, sejamos, no mundo, sentinelas da madrugada que sabem contemplar o verdadeiro rosto de Jesus Salvador, aquele que brilha na Páscoa, e descobrir novamente o rosto jovem e belo da Igreja, que brilha quando é missionária, acolhedora, livre, fiel, pobre de meios e rica no amor."

\section{Conclusão}

As palavras proferidas permitem-nos assegurar que Maria se tornou importante na comunidade cristã não apenas pela sua atitude, mas pelo que ela permitiu acontecer: Jesus na história. A sua relação com este filho e a sua vida de permanente escuta e silêncio, são a profunda realização do seu sim dado a Deus e dado a Jesus. Compreendamos que Maria não é a salvação, só Jesus é a Salvação. Maria é simplesmente uma jovem mulher, uma "mulher de fé", uma mãe singular; não uma deusa ou a quarta pessoa da Santíssima Trindade. Só por isso é que ela é, também, sinal da humanidade capaz de acolher e conter Deus na simplicidade, na interioridade e intimidade.

É um fato, que nos primeiros tempos do cristianismo existiram formas muito diversas de entender o lugar singular de Maria na Igreja e na História da salvação. ${ }^{20}$ Não podemos explicitar aqui esta diversidade. Consideramos importante, apenas, sublinhar que o papel de Maria na História da Salvação deve ser tratado e considerado com muita delicadeza intelectual e teológica. Se é indispensável evitar que se coloque o papel de Maria ao mesmo nível do de Jesus Cristo (LG 60-62), é importante que fique claro que Deus confiou a

\footnotetext{
${ }^{19}$ FRANCISCO. "Palavras do Papa Francisco na peregrinação de Fátima (Maio 2017)”. Disponível em: < http://www.papa2017.fatima.pt/pt/>. Acesso em 14 de maio de 2017.

${ }^{20}$ Cf. NADEAU, M.T. Quién es María? Hablar de la Virgen Hoy, pp. 29-31.
} 
Maria um ministério original, fazendo-a desempenhar um papel singular na história da salvação. Maria tem um lugar único na vida e mistério de Jesus Cristo, que se amplia à vida da Igreja. É nesta amplitude que se realiza o seu lugar na história da Salvação.

\section{Referências bibliográficas}

BROWN, R. E.; DONFRIED, K. P.; FITZMYER, J. A.; REUMANN, J. (Eds.). Mary in the New Testament. Philadelphia / New York: Fortress / Paulist, 1978.

FRANCISCO. "Palavras do Papa Francisco na peregrinação de Fátima (Maio 2017)". Disponível em: <http://www.papa2017.fatima.pt/pt/>. Acesso em 14 de maio de 2017.

GASPERIS, F. R. Maria di Nazaret: Ícona di Israele e della Chiesa. Magnano: Edizioni Qiqajon, 1997.

GROUPE DES DOMBES. Marie dans le dessein de Dieu et la communion des saints. Tome I: Dans l'histoire et l'Écriture. Paris: Bayard / Centurion, 1997.

IGNACIO DE ANTIOQUIA. "Carta a los esmirniotas III". Disponível em: $<$ http://www.apologeticacatolica.org/pt/patristica/patrist12.html $>$. Acesso em 22 de narço de 2017.

JOÃO PAULO II. Redemptoris Mater. São Paulo: Paulus, 1987.

JOUNEL, P. "Le culte de Marie". In: MARTIMORT, A. G. L'Église en Prière IV: La liturgie et le temps. Paris: Desclée, 1983.

MERCENIER, F. "La plus ancienne prière à la sainte Vierge". Questions Liturgiques 25 (1940), pp. 33-36.

MIRAVAlLE, M. I. (Ed.). Mary, Coredemptrix, Mediatrix, Advocate. Theological Foundations. Towards a papal definition? Santa Barbara, CA: Queenship Publishing, 1995.

NADEAU, M.T. Quién es María? Hablar de la Virgen Hoy. Madrid: San Pablo, 2002.

PAULO VI. Marialis Cultus. $\mathrm{N}^{\circ}$ 66. Disponível em: <http://w2.vatican. $\mathrm{va} /$ content/paul-vi/pt/apost_exhortations/documents/hf_p-vi_ exh_19740202_marialis-cultus.html $>$. Acesso em 12 de janeiro de 2017.

PELLETIER, A. M. "Marie, verus Israel et mère de l'Église". Christus 183 (1999), pp. 283-295. 
PERRIER, P. Karozoutha. Annonce orale de la bonne nouvelle em araméen et évangiles gréco-latin, Paris: Médiaspaul - Montréal / Paulines, 1986.

SESBOUE, B. "Marie, celle qui a cru". Christus 183 (1999), p. 269.

SESBOUE, B. "Peut-on encore parler de Marie?”. Christus 183 (1999), pp. 264-273.

VATICANO II.Lumen Gentium. Disponível em: $<$ http://www.vatican.va/archive/hist_councils/ii_vatican_council/documents/vat-ii_const_19641121_ lumen-gentium_po.html>. Acesso em 19 de janeiro de 2017.

VATICANO II. Gaudium et Spes. Disponível em: <http://www.vatican.va/archive/hist_councils/ii_vatican_council/documents/vat-ii_ const_19651207_gaudium-et-spes_po.html >. Acesso em 06 de fevereiro de 2017.

Luisa Maria Almendra

Doutora em Teologia Bíblica pela Universidade Católica Portuguesa Professora da Faculdade de Teologia da Universidade Católica Portuguesa Lisboa / Portugal E-mail: luisa.almendra@ft.lisboa.ucp.pt

Recebido em: 07/08/17

Aprovado em: 01/12/17 